\title{
Vernalização do alho para cultivo in vitro
}

Jony E. Yuri' ${ }^{1}$ José H. Mota'; Rovilson J. de Souza'; ${ }^{1}$ Geraldo M. de Resende²; Moacir Pasqual ${ }^{1}$

${ }^{1}$ UFLA, Depto. Agricultura, C. Postal 37, Lavras-MG; ${ }^{2}$ Embrapa Semi-Árido, C. Postal 23, 56300-970 Petrolina-PE; E-mail: jonyyuri@uol.com.br

\section{RESUMO}

Com o objetivo de avaliar o período de vernalização sobre a incidência do índice de pseudoperfilhamento em plantas de alho (Allium sativum L.) cultivadas in vitro, visando maior multiplicação, foi conduzido este experimento em laboratório da UFLA (MG). Utilizou-se o delineamento inteiramente casualizado com seis períodos de vernalização $(40 ; 50 ; 60 ; 70 ; 80$ e 90 dias) em câmara frigorífica a $5 \pm 2^{\circ} \mathrm{C}$, com quatro repetições, utilizando-se a cultivar Roxo Pérola de Caçador. O tratamento com 90 dias de vernalização foi o que apresentou os melhores resultados para as variáveis bulbo/ meristema/tubo, massa fresca total das plantas e dos bulbos com 1,81 bulbo/meristema/tubo, 235,32 mg plantas ${ }^{-1}$ e $110,51 \mathrm{mg} \mathrm{bulbo}^{-1}$, respectivamente. A massa fresca media por bulbo obtida não evidenciou diferenças significativas entre os tratamentos, no entanto, o tratamento com 90 dias de vernalização $\left(58,68 \mathrm{mg}^{\text {bulbo }}{ }^{-1}\right)$ apresentou-se com uma produção de bulbos $79,29 \%$ superior ao tratamento com 60 dias de vernalização, que demonstrou o pior resultado.

Palavras-chave: Allium sativum, cultura de tecidos, bulbos, índice de multiplicação.

\begin{abstract}
Garlic vernalization for in vitro cultivation

The vernalization time to obtain secondary growth of garlic plants (Allium sativum L.) was evaluated, through in vitro tissue culture technique at the Universidade Federal de Lavras, Minas Gerais State, Brazil. The experimental design was completely randomized with six vernalization periods $(40 ; 50 ; 60 ; 70 ; 80$ and 90 days) in refrigerator chamber at $5 \pm 2^{\circ} \mathrm{C}$, with four replicates. The cultivar Roxo Pérola de Caçador was used in the experiment. The treatment evaluating 90 days of vernalization presented the best results for the ratio bulbs/meristem/tube, plant total fresh matter and bulbs with $1,81 \mathrm{bulbs} / \mathrm{meristem} / \mathrm{tube}, 235.32 \mathrm{mg} \mathrm{plant}^{-1}$ and $110.51 \mathrm{mg} \mathrm{bulb}^{-1}$, respectively. No significant differences among treatments were observed for average fresh matter per bulb. However, 90 days of vernalization with $58.68 \mathrm{mg}^{\text {bulb }}{ }^{-1}$ was $79.29 \%$ superior to 60 days of vernalization, presenting the worst result.
\end{abstract}

Keywords: Allium sativum, tissue culture, fresh matter of bulb, multiplication index.

\section{(Recebido para publicação em 23 de junho de 2003 e aceito em 16 de abril de 2004)}

A produção brasileira de alho para a safra 2002/2003 foi de $120 \mathrm{mil}$ toneladas, entre alho comum e nobre, perfazendo cerca de $64 \%$ do total da demanda. Dessa forma, o Brasil importou cerca de 68.000 toneladas de alho do tipo 5, ou de qualidade superior, para o seu abastecimento interno (Carvalho, 2002).

Entre as cultivares utilizadas no Brasil destaca-se a Roxo Pérola de Caçador que apresenta características organolépticas muito apreciadas pelos consumidores brasileiros e com potencialidades de concorrer com os alhos importados. Segundo Biasi e Mueller (1989), esta cultivar apresenta bulbos arroxeados, com túnicas branco perola, bulbilhos arroxeados em número de 5 a 15 , com predisposição ao pseudoperfilhamento em campo, com produtividade variando de 10 a $14 \mathrm{tha}^{-1}$

A propagação da cultura do alho no campo é feita somente por meio de bulbilhos. Cultivado geração após geração, ocorre gradativamente um acúmulo de viroses com efeitos diretos na redução da produtividade. Segundo
Silva et al. (2000) as viroses não chegam a causar a morte das plantas de alho, porém sua importância foi subestimada durante muito tempo e só recentemente essas doenças passaram a receber maior atenção dos pesquisadores.

As técnicas de cultura de tecidos têm sido empregadas na obtenção de plantas de alho livres de vírus. Dentre elas, a cultura de ápices caulinares é considerada um instrumento valioso na obtenção de plantas livres de vírus e de outros patógenos, na propagação clonal rápida e no desenvolvimento de cultivares melhoradas (tolerância a doenças, a herbicidas, à salinidade e à seca entre outros). Sendo que esta técnica possibilita a preservação de germoplasma e um melhor entendimento dos princípios básicos relacionados com fisiologia, bioquímica e no desenvolvimento das plantas (Vaz, 1986). A associação da cultura de tecidos com a termoterapia tem colaborado para o aumento da porcentagem na obtenção de plantas livres de doenças (Conci e Nome, 1991; Robert et al., 1998). Torres et al. (2000) obtiveram, com a cv. Amarante, 54\% de plantas livres de vírus associando cultura de tecidos a termoterapia a seco, com a exposição dos bulbilhos à temperatura de $37^{\circ} \mathrm{C}$ durante 35 dias.

Dentre as anormalidades fisiológicas que ocorrem no alho, o perfilhamento ou pseudoperfilhamento é considerado uma característica comercialmente indesejável, depreciando o produto e reduzindo a produtividade (Burba, 1983). Diversos fatores têm sido relacionados com a ocorrência de pseudoperfilhamento, dentre eles o fotoperíodo e temperatura (Silva, 1982; Carmo et al., 1985), o excesso de água próxima à colheita e o excesso de adubação nitrogenada também contribui para esta anormalidade.

Porém a limpeza clonal, via cultura de ápices caulinares, é dificultada pela reduzida taxa de multiplicação e conseqüentemente pouco material para produção comercial. Além disso o material proveniente da limpeza clonal é, rapidamente sujeito à infecção dos bulbos. 


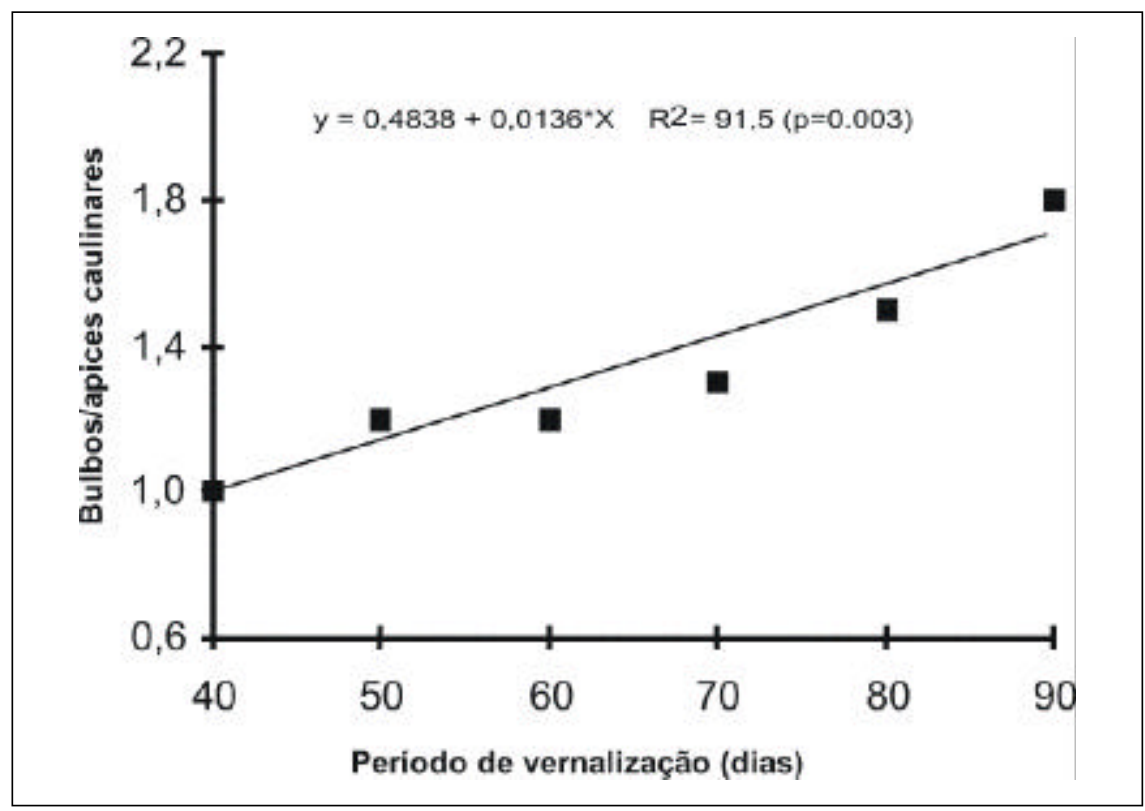

Figura 1. Número de bulbos por ameristema em função do período de vernalização. Lavras, UFLA, 2002.

Uma possível alternativa para promover maior rendimento na multiplicação in vitro estaria na utilização de baixas temperaturas (vernalização) dos bulbos em câmara frigorífica para posterior retirada dos ápice caulinares para cultivo in vitro.

Braz et al. (1997), observaram que o cultivo a campo do alho vernalizando a $4^{\circ} \mathrm{C}$, resultou nos melhores resultados para a cv. Quitéria, quando vernalizado por 30 e 40 dias.

Utilizando uma cultivar local denominada Howaito Roppen (tardia) com bulbos armazenados durante quatro meses a uma temperatura mínima de $20^{\circ} \mathrm{C}$ e posteriormente vernalizados por 30 ou 60 dias a $5^{\circ} \mathrm{C}$, Ferreira et al. (1991), observaram que a vernalização (0 a 39 dias a $4 \pm 1^{\circ} \mathrm{C}$ ) das cultivares Quitéria e Chonan foi imprescindível para o aumento da produção de bulbos e redução da percentagem de charutos (plantas improdutivas).

Kimoto et al. (1996), vernalizando a cultivar Roxa Pérola de Caçador por 45 dias a $4^{\circ} \mathrm{C}$, verificaram produtividade total de $2944 \mathrm{~kg} /$ ha e somente $16,6 \%$ de pseudoperfilhamento, que é um índice baixo, pois esta anomalia pode chegar a $100 \%$ da produção.

O presente trabalho teve como objetivo avaliar o período de vernalização sobre a incidência de perfilhamento do alho in vitro por meio da cultura de ápices caulinares, visando maior índice de multiplicação.

\section{MATERIAL E MÉTODOS}

O experimento foi conduzido no Laboratórios de Cultura de Tecidos da Universidade Federal de Lavras. Utilizou-se o delineamento inteiramente casualizado com seis tratamentos, correspondentes aos períodos de vernalização $(40 ; 50 ; 60 ; 70 ; 80$ e 90 dias) em câmara frigorífica a $5 \pm 2{ }^{\circ} \mathrm{C}$, com quatro repetições. A cultivar fornecedora dos ápices caulinares foi a Roxo Pérola de Caçador proveniente de Santa Juliana, MG. No dia 27/03/02 foi armazenada a primeira amostra de bulbos de alho, correspondente ao tratamento de 90 dias de vernalização. $\mathrm{Na}$ seqüência, a cada 10 dias, foram armazenadas as amostras referentes aos demais tratamentos, sendo a última amostra colocada na câmara fria no dia 16/ 05/02, que correspondeu a 40 dias de vernalização. Todas as amostras foram retiradas da câmara fria no dia 25/06/ 2002 e encaminhadas ao laboratório.

Após a retirada da câmara frigorífica os bulbos foram debulhados, lavados em água com detergente por 5 minutos e posteriormente lavados apenas em água corrente. Em seguida as folhas meristemáticas foram imersas em hipoclorito de sódio $(2 \%)$ na concentração de 1:1 (v/v) durante 15 minutos. Após essa desinfestação, as mesmas foram lavadas em água autoclavada por três vezes para retirar o excesso de hipoclorito, no interior de uma câmara de fluxo laminar. Na sequiência os ápices caulinares retirados foram colocados em tubos de ensaio com $12 \mathrm{ml}$ de meio MS (Murashige e Skoog, 1962). Cada tubo recebeu apenas um ápice meristematico. Os tubos contendo os ápices caulinares foram colocados em ambiente com luminosidade de \pm 2000 lux, e temperatura $\left(20^{\circ} \mathrm{C}\right)$ controlada.

As avaliações foram realizadas no dia 30/09/2002, com 97 dias após a inoculação, sendo analisados a massa fresca total das plantas (mg), massa fresca total dos bulbos (mg), número de bulbos (piorras, microbulbos ou bulbinhos) obtidos a partir de um ápice caulinar e massa fresca média por bulbo (mg). As características avaliadas foram posteriormente submetidas a análise de regressão, de acordo com o esquema sugerido por Pimentel Gomes (1990).

\section{RESULTADOS E DISCUSSÃO}

Após três meses que os ápices caulinares foram colocados nos tubos houve completa formação dos bulbos, verificando-se diferenças significativas entre os tratamentos, com exceção da característica massa fresca média por bulbo.

Houve comportamento linear (Figura 1), para número de bulbos por ápices caulinares, em função do período de vernalização. O período de 90 dias de vernalização (1,81 bulbo/ápice caulinar) foi o que promoveu maior incremento em número de bulbos com 70,7\% em relação ao menor período de vernalização (40 dias). Esta característica é de grande relevância quando se leva em consideração que um dos grandes entraves da limpeza de vírus por meio da cultura de tecidos é a baixa de multiplicação dos ápices caulinares. Este resultado porém foi inferior ao obtido por Rossi et al. (1995) que obtiveram para a cv. Piacentiano Bianco, uma proliferação no número de bulbos de 1:4,5 utilizando o meio MS modifica- 
do, acrescido de TDZ. Entretanto, devese levar em conta que essa comparação diz respeito apenas à magnitude dos dados obtidos, uma vez que a cultivar Piacentiano Bianco não foi utilizada no presente trabalho.

A massa fresca total das plantas e de bulbos evidenciaram efeito quadrático (Figura 2), em que o período de vernalização de 90 dias apresentou os melhores resultados, com 235,32 e 110,51 mg planta ${ }^{-1}$, respectivamente. Estes resultados são corrobados com Ferreira et al. (1981) que observaram aumento do número de bulbilhos quando do aumento do período de vernalização. Observa-se que o processo de vernalização estimula o acumulo de citocininas e giberelinas, e quando os bulbilhos são colocados em condições ótimas de desenvolvimento, ocorre brotação precoce, e conseqüentemente maior desenvolvimento da planta.

A vernalização do alho modifica o balanço hormonal, provocando na planta a quebra da dormência e aceleração na brotação dos bulbilhos (Ferreira et al, 1986). De acordo com Carvalho et al (1980), a brotação dos bulbos é acentuada quanto maior for o período de vernalização.

Já em campo Seno et al, (1993) observaram em experimento que a vernalização de 40 dias resultou em maior porcentagem de superbrotamento, sendo que a menor porcentagem foi observada com 60 dias. Segundo Souza (1990), a temperatura além de interferir na bulbificação, pode influenciar nas características comerciais do alho. Os efeitos da baixa temperatura em préplantio, promove o perfilhamento, e quanto maior o período de vernalização maior e a porcentagem de perfilhamento, esse resultado e também relatado por Mann e Minges (1958) e Burba (1983).

A massa fresca média por bulbo obtida no presente trabalho apesar de não ter evidenciado diferenças significativas entre os tratamentos, evidencia um valor superior para o tratamento com 90 dias de vernalização, com 58,68 mg bulbo $^{-1}$, que comparativamente a menor massa fresca media alcançada pelo tratamento de 60 dias de vernalização mostrou-se 79,29\% superior.

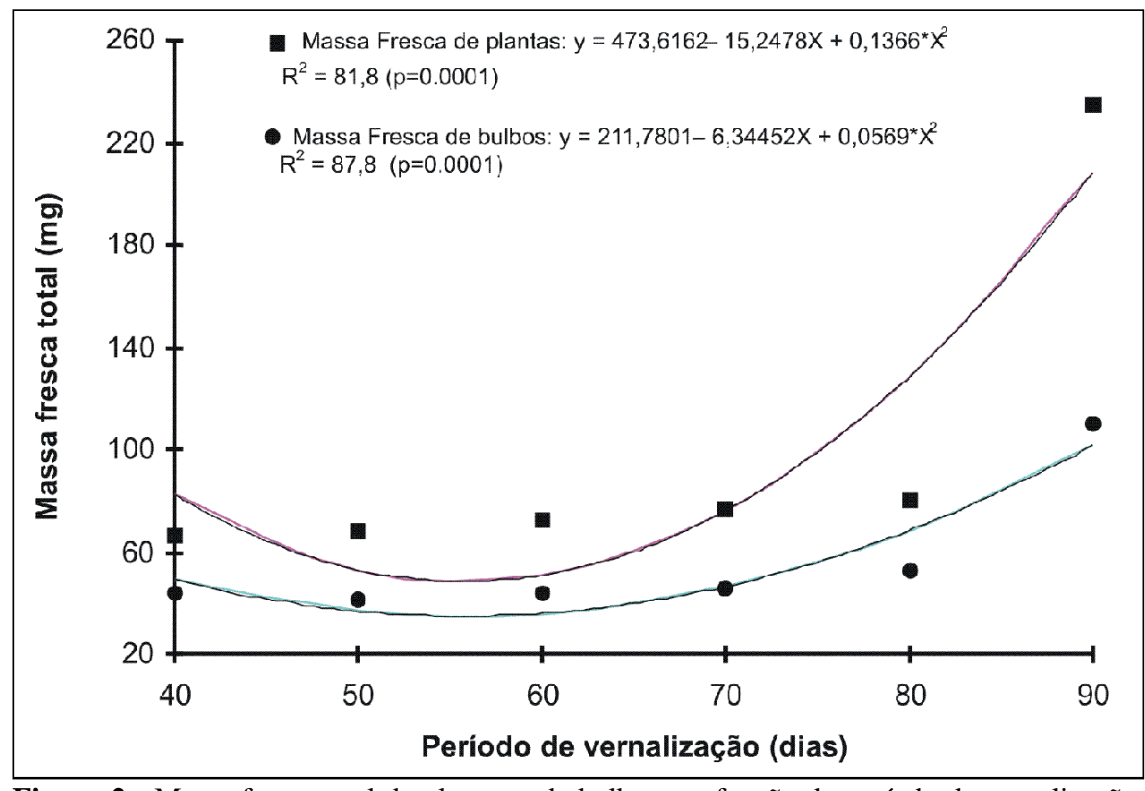

Figura 2. Massa fresca total de plantas e de bulbos em função do período de vernalização. Lavras, UFLA, 2002.

Pesquisas realizadas ao nível de campo por Resende et al. (1995 e 1999), comparando materiais provenientes de cultura de ápice caulinar com materiais multiplicados de forma convencional, comprovaram o aumento na produção e o acúmulo de matéria seca em clones provenientes da utilização desta técnica. Segundo Resende (1993) a técnica de cultura de tecidos recupera o vigor vegetativo e consequientemente a produtividade das cultivares, ao quebrar o ciclo reprodutivo dos vírus.

Em função dos resultados obtidos, 90 dias de vernalização em câmara frigorífica a $5 \pm 2^{\circ} \mathrm{C}$, para a cultivar Roxo Pérola de Caçador por meio da técnica de cultura de tecidos utilizando ápices caulinares é o tratamento mais recomendado por apresentar maior número de bulbos por ápices, massa fresca total de plantas e bulbos e massa fresca média de bulbo, o que possibilitará melhor índice de multiplicação de bulbos e conseqüentemente maior eficácia e rapidez do método na multiplicação clonal.

\section{LITERATURA CITADA}

BIASI, J.; MUELLER, S. Alho seleção Caçador Dez, Vinte e Trinta. Horticultura Brasileira: Brasília, v.7, n.1, p.44, 1989. (Resumo) BRAZ, L.T.; SILVA, E.J.; CASTELLANE, P.D The effects of pre-planting refrigeration on bulbs over the development and yield of garlic "Chines", "Contestado" and "Quitéria". Acta Horticulturae, n.433, p.499-505, 1997.
BURBA, J.L. Efeitos do manejo de alho-semente (Allium sativum L.) sobre a dormência, crescimento e produção da cultivar Chonan. Viçosa:UFV, 1983. 112 p. (;Tese mestrado)

CARMO, C.A.S.; CASALI, V.W.D.; THIEBAUT, J.T.L.; SILVA, J.F.; MEDINA, P.V.L. Influência da temperatura no índice de perfilhamento em plantio de alho. Horticultura Brasileira, Brasília, v.3, n.1, p.65, 1985. (Resumo)

CARVALHO, M.A. Alho: informativo especial. Julh. 2002. Disponível em:<http:// www. conab.gov.br/política-agricola/Conjuntura Semanal>. Acesso em 10 set. 2002.

CARVALHO, C.G.S.; MONNERAT, P.H.; CARVALHO, Y. Efeito de tratamentos pré-plantio de bulbilhos de alho cv. Amarante. Revista de Olericultura, Viçosa, v.15, n.1, p.165-173, 1980. CONCI, V.C.; NOME, S.F. Virus-free garlic (Allium sativurn L.) plants obtained by thermotherapy and meristem tip culture. Journal Phytopathology, v.132, n.3, p.186-192,1991.

FERREIRA, F.A.; CARDOSO, M.R.O., FARIA, J.F. Efeito de baixas temperaturas no pré-plantio em alho (Allium sativum L.) cultivar Chonan. In: EPAMIG. Projeto Olericultura. Belo Horizonte,1981. p.23-27. (Relatório anual, 77/78).

FERREIRA, F.A.; CASALI, V.W.D.; SOARES, J.G. Dormência de bulbos de alho. Informe Agropecuário: Belo Horizonte, v.12, n.142, p.37, 1986.

FERREIRA, F.A.; CASALI, W.V.D.; ÁLVARES, V.H.; RESENDE, G.M. Desenvolvimento de alho cvs. Chonan e Quitéria após armazenamento refrigerado. Horticultura Brasileira: Brasília, v.9, n.1, p.8-10, 1991.

KIMOTO, T.; CARDOSO, A.I.I.; CHENG. A.P.; KAMITSUSUJI, M.K.; LIMA, M.C.C.; TSUTSUMI, C.Y.; GOTO, R. Desvernalização em alho semente devido ao atraso no plantio após a retirada da camâra frigorífica. Horticultura Brasileira: Brasília, v.14, n.1, p.53-55, 1996. 
MANN, L.K.; MINGES, P.A. Growth and bulbing of garlic (Allium sativum L.) in response to storage temperature of planting stocks, day length and planting date. Hilgardia, v.27, n.15, p.385-419, 1958

MURASHIGE, T.; SKOOG, F. A revised médium for rapid growth and biossays with tobacco tissue cultures. Physiologia Plantarum, v.15, n.3, p.473497, 1962.

PIMENTEL GOMES, F. Curso de estatística experimental. 13.ed. São Paulo: Nobel, 1990. 468 p. RESENDE, F.V. Comportamento em condições de campo, de plantas de alho (Allium sativum L.) obtidas por cultura de meristemas. Lavras: ESAL, 1993. 63 p. (Tese mestrado)

RESENDE, F.V.; SOUZA, R.J.; PASQUAL, M Comportamento em condições de campo de clones de alho obtido por cultura de meristema. Horticultura Brasileira: Brasília, v.13, n.1, p.4446, 1995.
RESENDE, F.V.; SOUZA, R.J.; FAQUIN, V.; RESENDE, J.T.V. Comparação de crescimento e produção entre alho proveniente de cultura de tecidos e de multiplicação convencional. Horticultura Brasileira: Brasília, v.17, n.2, p.118124, 1999.

ROBERT, U.; ZEL, J.; RAVNIKAR, M.

Thermotherapy in vírus elimination from garlic: influences on shoot multiplicatin from meristems and bulb formtion in vitro. Scientia Horticulturae, v.73, n.4,p.193-202, 1998.

ROSSI, V.; MARANI, F.; BABITI, A.L. Phenylurea derivatives for micropropagation of garlic meristems. Acta Horticulturae. n.394, p.263-271, 1995.

SILVA, E.C.; SOUZA, R.J.; SANTOS, V.S. Efeitos do tempo de frigorificação em cultivares de alho (Allium sativum L.) provenientes de cultura de meristemas. Ciência e Agrotecnologia, Lavras, v.24, n.4, p.939-946, 2000.
SILVA, J.L.O. Análise de crescimento de alho (Allium sativum L.) cultivar Chonan sob três períodos de frigorificação pré-plantio dos bulbos. Lavras:UFLA. 1982. 76 p. (Tese mestrado).

SOUZA, R.J. Influência do nitrogênio, potássio, cycocel e paclobutrazol na cultura do alho (Allium sativum L.). Viçosa:UFV.1990. 143 p. (Tese dutorado)

TAKAGI, H.; QU, Y. Effect of light quality, photoperiod and cold treatment on in vitro bulbing of garlic shoot tip. Acta Horticulturae, n.393, p.181-188, 1995.

TORRES, A.C.; FAJARDO, T.V.; DUSI, A.N.; RESENDE, R.O.; BUSO, J.A. Shoot tip culture and thermotherapy for recovering vírus-free plants of garlic. Horticultura Brasileira: Brasília, v.18, n.3, p.192-195, 2.000.

VAZ, R.L. Cultura de tecidos: potencial e aplicação. Anais... Brasília: EMBRAPA-DDT, p. 9-10. 1986. 